Gut, 1978, 19, 108-113

\title{
Escherichia coli antibodies in patients with inflammatory bowel disease
}

\author{
SOAD TABAQCHALI ${ }^{1}$, D. P. O’DONOGHUE, AND K. A. BETTELHEIM
}

From the Departments of Medical Microbiology and Gastroenterology, St. Bartholomew's Hospital, London

SUMMARY Sera from 30 patients with inflammatory bowel disease (IBD) (16 with Crohn's disease (CD) and 14 with ulcerative colitis (UC)) were assayed for the presence of antibodies against 159 Escherichia coli $\mathrm{O}$-antigens and compared with sera from 16 matched control subjects. The majority of patients with IBD had agglutinating antibodies to a higher number of Escherichia coli O-antigens and in higher titres than the control group. The number of positive agglutinins was O-33 mean 13.8 in CD, 0-26 mean 7.9 for UC, and O-7 mean 1.5 in controls. Eight patients with IBD and arthropathy had antibodies to fewer O-antigens (O-7 mean 3.2). The antibodies were in the IgG and IgM, in titres corresponding to original values. No specific O-serotypes were associated with IBD. Common serotypes, R-plasmid carrying serotypes, and those associated with shigella-like adult diarrhoea were detected. $\mathrm{O} 14$ was detected only in five patients and $0119 \mathrm{in}$ none. There was no correlation between the number of Escherichia coli agglutinins and the site and severity of the disease or type of therapy. It is suggested that the presence of the high numbers of Escherichia coli antibodies is secondary to the disease process and is unlikely to be causally involved in the pathogenesis of the disease, but may play a role in the perpetuation of the disease and in the extraintestinal complications.

The involvement of immunological mechanisms in the pathogenesis of inflammatory bowel disease (IBD) has been extensively investigated (Goldgraber and Kirsner, 1958; Broberger and Perlmann, 1959; Perlmann et al., 1965; Wright and Truelove, 1966). Broberger and Perlmann (1959) demonstrated the presence of an antibody in the sera of patients with ulcerative colitis which reacted with an antigen derived from human colon. The possibility that antigens derived from intestinal bacterial products may cause this immune stimulation led to the consideration that the intestinal flora may play a pathogenetic role, particularly Escherichia coli 014. Escherichia coli $\mathrm{O} 14$ was found to have a common antigen which reacted with human colonic mucosa (Perlmann et al., 1965; 1967; Lagercrantz et al., 1968) and autoantibodies to gut mucosa could be produced by injection of bacteria (Asherson and Holborow, 1966). Further work demonstrated increased incidence of antibodies to Escherichia coli $\mathrm{O} 14$ in the serum of patients with ulcerative colitis and Crohn's

${ }^{1}$ Address for reprint requests: Dr S. Tabaqchali, Department of Medical Microbiology, St. Bartholomew's Hospital, London E.C.1.

Received for publication 4 August 1977 disease compared with controls (Perlmann et al., 1965; Thayer et al., 1969; Bull and Ignaczak, 1973). Antigens derived from Escherichia coli $\mathrm{O} 14$ and another serotype, Escherichia coli O119.K69 (B14) were also found to induce lymphocytes to become cytotoxic to colonic mucosa (Shorter et al., 1970; Bull and Ignaczak, 1973). These findings led to the suggestion that these specific Escherichia coli serotypes are causally involved in the pathogenesis of inflammatory bowel disease.

In order to test this hypothesis, and because the intestinal Escherichia coli flora can contain a variety of serotypes over a period of time (Bettelheim et al., 1972; Shooter et al., 1977; Tabaqchali et al., 1977), it was considered that an assay of antibodies to all currently accepted 159 Escherichia coli O-antigens in the serum of patients with ulcerative colitis and Crohn's disease might give a better understanding of the bacterial role in these patients, and also determine if the antigenic stimulus is limited to the specific serotypes as previously reported, or if it is a widespread reaction.

\section{Methods}

Blood specimens were obtained from 30 patients 
Table 1 Clinical data

\begin{tabular}{lllllll}
\hline $\begin{array}{l}\text { Patient } \\
\text { group }\end{array}$ & No. & \multicolumn{2}{l}{ Age $(y r)$} & & \multicolumn{2}{l}{ Sex } \\
\cline { 3 - 4 } \cline { 6 - 7 } & & Mean & Range & & $F$ & $M$ \\
\hline $\begin{array}{l}\text { Controls } \\
\text { Crohn's }\end{array}$ & 16 & $33 \cdot 5$ & $19-75$ & & 7 \\
$\begin{array}{l}\text { disease } \\
\begin{array}{l}\text { Ulcerative } \\
\text { colitis }\end{array}\end{array}$ & 16 & $33 \cdot 7$ & $20-71$ & & 12 & 4 \\
\hline
\end{tabular}

with inflammatory bowel disease (IBD), 16 of whom had Crohn's disease (CD) and 14 had ulcerative colitis (UC), and 16 age and sex-matched control subjects, eight healthy adults and eight inpatients with no evidence of IBD or bacterial infections (Table 1). The sera were separated and stored in 1 $\mathrm{ml}$ aliquots at $-20^{\circ} \mathrm{C}$. No aliquot was thawed and refrozen more than once. The diagnosis was confirmed by clinical, radiological, endoscopic, and histological criteria. In patients with Crohn's disease, the disease in four was confined to the small bowel; in $\mathbf{1 0}$ the disease was limited to the colon and two had ileocolonic involvement. In patients with ulcerative colitis seven had limited involvement of rectum and sigmoid, and seven had extensive involvement of the colon. Disease activity was assessed at the time the serum was obtained and scored as mild, moderate, or severe. Five patients with Crohn's disease were receiving corticosteroid therapy, two salicylazosulphapyridine (salazopyrine), and nine no therapy. Two patients with ulcerative colitis were on corticosteroids, three on salazopyrine; two received both drugs and five had no therapy. No patient had coexisting liver disease. Serum immunoglobulin estimations were normal in all patients and in the control subjects.

Eight of the 30 patients with inflammatory bowel disease had associated arthropathy (six ankylosing spondylitis, two large joint involvement), five patients had ulcerative colitis and three had Crohn's disease. These will be presented as a separate group in the Results section.

\section{AgGlutination STUdies}

Strains representing the classical Escherichia coli Oantigens were used. They included all $O$ types from O1 to 0163 except O31, O47, O67, O72, O94, and 0122 which have been removed from the internationally accepted scheme for various reasons. Both varieties of O18, and 0112 (O18ab, O18ac, O112ab, and 0112ac) were included in this study.

Standard $O$ suspensions were prepared by growing these organisms in nutrient broth (Oxoid No. 3) for 18 hours, heating to $100^{\circ} \mathrm{C}$ in a water bath for one hour, and preserving with $0.05 \%$ formaldehyde on cooling. As controls, $O$ sera raised in rabbits according to the methods of Ewing (1956-57) were employed.

All agglutination studies were performed in WHO trays. The patients sera were diluted to $1 / 100(\mathrm{v} / \mathrm{v})$ with $0.85 \%$ aqueous sodium chloride $(\mathrm{w} / \mathrm{v})$ containing $1: 10000$ thiomersalate $(\mathrm{w} / \mathrm{v})$ as preservative; $0 \cdot 2$ $\mathrm{ml}$ of each patient's diluted serum was tested against an equal volume of each Escherichia coli suspension. Each suspension was simultaneously tested against a similar dilution of specific rabbit antiserum as positive control and saline as a negative control.

The trays were examined visually for agglutination after 18 hours' incubation at $50^{\circ} \mathrm{C}$. Agglutination was considered to have occurred when there was definite clumping at the bottom of the well, the supernatant solution was completely clear and, on tapping, the agglutinated clumps were visible. Control wells of saline mixed with $O$ suspensions appeared uniformly turbid after similar treatment (Bettelheim, 1969). A 'positive' test was taken as one giving a titre of $1 / 200$. The antibody titres were determined by doubling dilutions on all positive reactions.

CHARACTERISATION OF IMMUNOGLOBULINS Selected sera giving positive high titres were subjected to sucrose gradient ultracentrifugation and subdivided into six fractions using the method described by Desmyter et al. (1971). Each of these fractions was titrated against some of the antigens previously found to give high titres. This method separates IgG and IgM fractions but IgA is not distinguishable. In a preliminary study with Escherichia coli 01 specific serum prepared in rabbits, it was found that the agglutinating antibodies were not affected by this treatment.

\section{Results}

The number of the different Escherichia coli serotypes to which antibody was present in the serum from each patient in the different disease groups is shown in the Figure. The majority of patients with inflammatory bowel disease had higher numbers of agglutinating antibodies to Escherichia coli than the control group. In each group there was a variation in the number of positive reactions, ranging from O-33 in patients with Crohn's disease, O-26 in patients with ulcerative colitis, and 0-7 in patients with inflammatory bowel disease and arthropathy and in control subjects. The frequencies of positive reactions were 13.8 per patient in Crohn's disease, $\mathbf{7 . 9}$ for ulcerative colitis, $3 \cdot 2$ for inflammatory bowel disease and arthropathy, and 1.56 in the control group. There was no correlation between the number 


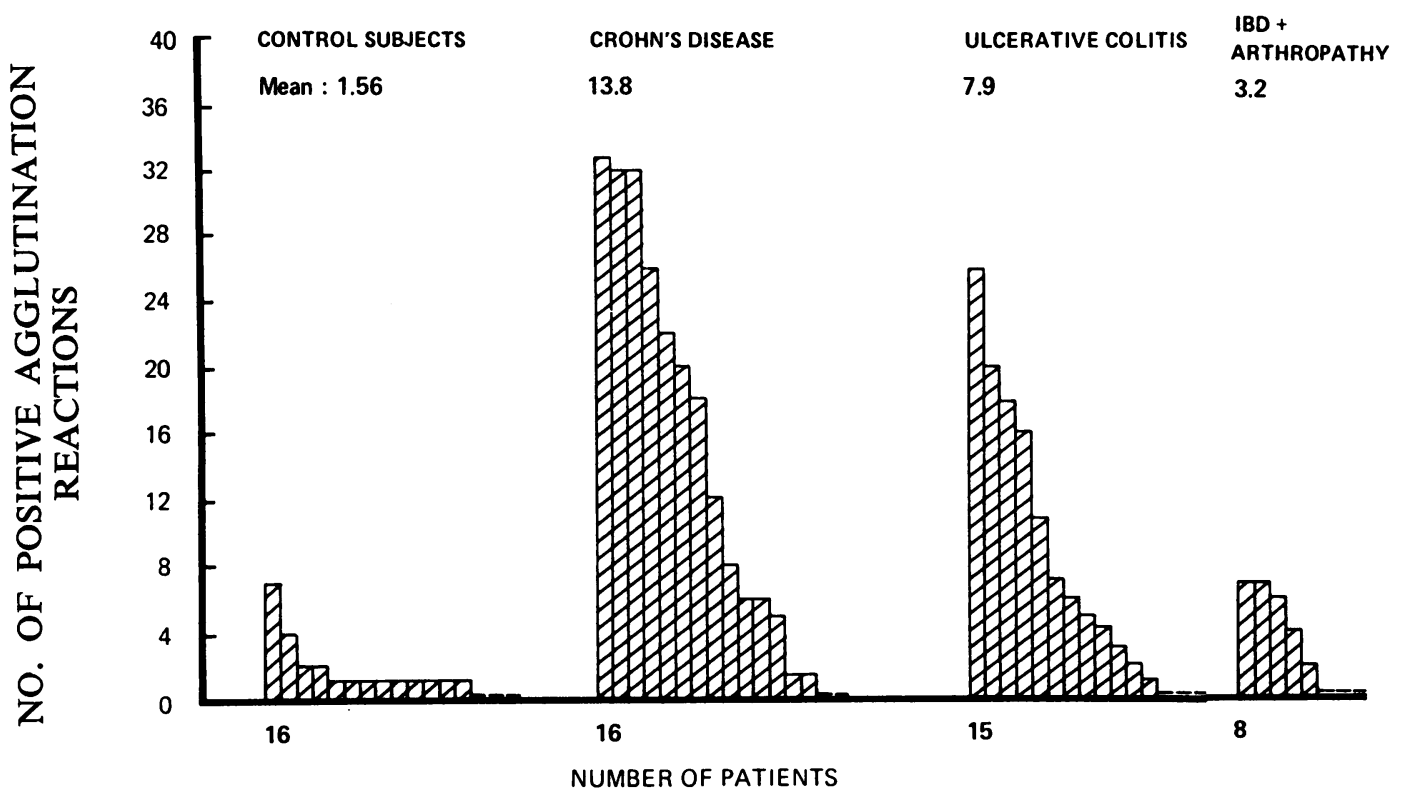

Figure The numbers of E. coli serotypes to which antibodies were present in the different groups.

of positive reactions and the site of the lesion in Crohn's disease or ulcerative colitis, the severity of the disease, or the type of therapy.

The agglutinin titres found in the different groups of patients studied and the number of patients in whom these were present are shown in Table 2. The titres ranged from 1:200 to $1: 6400$. The highest antibody titres against Escherichia coli O-antigens were found in patients with Crohn's disease, and to a lesser extent in patients with ulcerative colitis. These high titres were distributed among several patients and not limited to a few. A greater number of patients with inflammatory bowel disease had higher titres than those with IBD and arthropathy or control subjects.

Table 2 Distribution of agglutinin titres against Escherichia coli in the different patient groups

\begin{tabular}{|c|c|c|c|c|}
\hline No. of patients studied & $\begin{array}{l}\text { Control } \\
16\end{array}$ & $\begin{array}{l}\text { Crohn's } \\
\text { disease } \\
16\end{array}$ & $\begin{array}{l}\text { Ulcerative } \\
\text { colitis } \\
15\end{array}$ & $\begin{array}{l}\text { IBD }+ \\
\text { arthropathy } \\
8\end{array}$ \\
\hline \multicolumn{5}{|l|}{ Agglutinin titres } \\
\hline $\begin{array}{l}1 / 200 \\
1 / 400 \\
1 / 800 \\
1 / 1600 \\
1 / 3200 \\
1 / 6400\end{array}$ & $\begin{aligned} & 14(11) \\
& 6(4) \\
& 3(2) \\
& 2(1) \\
& 0 \\
& 0\end{aligned}$ & $\begin{aligned} 89 & (11) \\
77 & (12) \\
48 & (9) \\
5 & (5) \\
1 & (1) \\
2 & (1)\end{aligned}$ & $\begin{aligned} 52 & (9) \\
40 & (11) \\
23 & (8) \\
3 & (3) \\
1 & (1) \\
0 & \end{aligned}$ & $\begin{array}{r}16(4) \\
5(4) \\
2(2) \\
0 \\
0 \\
0\end{array}$ \\
\hline Total number & 25 & 222 & 119 & 23 \\
\hline
\end{tabular}

IBD: inflammatory bowel disease.

Figures in parentheses: number of patients in whom the corresponding number of positive titres were found.
The number of positive agglutination reactions to the common Escherichia coli $\mathbf{O}$ groups is shown in Table 3. There were a substantial number of positive agglutination reactions to the common strains causing urinary tract infection and also to the common $\mathbf{R}$ factor strains. There were minimal reactions with the strains known to cause infantile diarrhoea. Only five patients and one control subject had positive reaction to 014 and none to 0119 .

The agglutinating antibodies to the serotypes most

Table 3 Number of positive agglutination reactions to common Escherichia coli $O$-groups

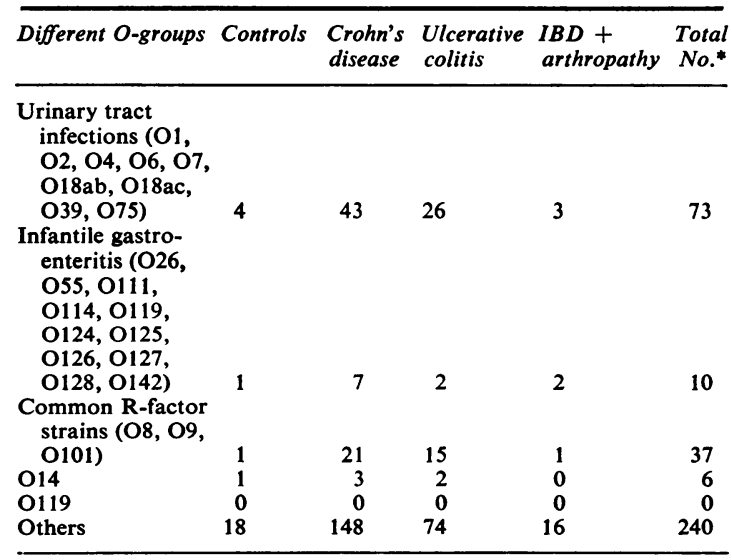

_. Excluding patients with associated arthropathy. 
Table $4 \quad O$-groups most commonly detected in different patients

\begin{tabular}{llllll}
\hline O-group & \multicolumn{5}{l}{ Number of patients with positive reactions } \\
\cline { 2 - 6 } & Controls & $\begin{array}{l}\text { Crohn's } \\
\text { disease }\end{array}$ & $\begin{array}{l}\text { Ulcerative } \\
\text { colitis }\end{array}$ & $\begin{array}{l}\text { IBD }+ \\
\text { arthropathy }\end{array}$ & $\begin{array}{l}\text { Total } \\
\text { no. }\end{array}$ \\
\hline O8 & 1 & 10 & 9 & 0 & 20 \\
O136 & 3 & 7 & 5 & 1 & 15 \\
O144 & 2 & 5 & 5 & 1 & 12 \\
O9 & 0 & 8 & 3 & 1 & 11 \\
O7 & 0 & 6 & 4 & 0 & 10 \\
O70 & 1 & 5 & 4 & 0 & 10 \\
O5 & 0 & 5 & 4 & 2 & 9 \\
O18c & 0 & 7 & 2 & 1 & 9 \\
O16 & 0 & 7 & 2 & 0 & 9 \\
O2 & 1 & 5 & 3 & 0 & 9 \\
\hline
\end{tabular}

*Excluding patients with associated arthropathy.

Table 5 Immunoglobulin class reacting with $E$. coli antigens

\begin{tabular}{|c|c|c|c|c|c|c|c|c|}
\hline \multirow{2}{*}{$\begin{array}{l}\text { Patient } \\
\text { groups } \\
\text { and nos. }\end{array}$} & \multirow{2}{*}{$\begin{array}{l}\text { Serotype } \\
\text { tested }\end{array}$} & \multirow{2}{*}{$\begin{array}{l}\text { Original } \\
\text { titre }\end{array}$} & \multicolumn{6}{|c|}{ Ig class and titres } \\
\hline & & & $1 / 80$ & $1 / 160$ & $1 / 320$ & $1 / 640$ & & 1280 \\
\hline \multirow{2}{*}{\multicolumn{9}{|c|}{$\begin{array}{l}\text { Controls } \\
1 \\
\text { Ulcer- } \\
\text { ative } \\
\text { colitis }\end{array}$}} \\
\hline & & & & & & & & \\
\hline 1 & 08 & $1 / 1600$ & ++ & ++ & ++ & ++ & - & + \\
\hline 2 & 0161 & $1 / 1600$ & ++ & ++ & ++ & +- & + & - \\
\hline 3 & 08 & $1 / 800$ & ++ & -+ & -+ & -- & - & - \\
\hline & 075 & $1 / 800$ & -+ & -+ & -+ & -+ & - & - \\
\hline \multicolumn{9}{|l|}{$\begin{array}{l}\text { Crohn's } \\
\text { disease }\end{array}$} \\
\hline 1 & $\left\{\begin{array}{l}08 \\
18 a c\end{array}\right.$ & $1 / 1600$ & ++ & ++ & -+ & -+ & - & + \\
\hline 2 & $\begin{array}{l}18 \mathrm{ac} \\
0136\end{array}$ & $1 / 400$ & ++ & ++ & ++ & -- & - & - \\
\hline 2 & $\int_{05}^{0136}$ & $\begin{array}{l}1 / 800 \\
1 / 1600\end{array}$ & $\overline{+}+$ & $=+$ & $\begin{array}{l}-+ \\
-+\end{array}$ & -+ & - & $\bar{t}$ \\
\hline 3 & $18 \mathrm{ac}$ & $1 / 800$ & ++ & -+ & -+ & -+ & - & - \\
\hline
\end{tabular}

frequently occurring in the different groups of patients are shown in Table 4. Although agglutinins to $08,0136,0144$ were present more frequently, there was no single serotype present in all patients. Apart from antibodies to $\mathrm{O} 144$ and $\mathrm{O} 136$, those to 0124 and 06 were also present frequently in titres greater than 1:800.

\section{CHARACTERISATION OF IMMUNOGLOBULIN ASSOCIATED WITH Escherichia coli \\ ANTIBODY}

IgG and IgM were the two immunoglobulin fractions to which the Escherichia coli $\mathrm{O}$-antigen reacted. The titres of the positive reactions to the specific strains are shown in Table 5. The titres obtained with the immunoglobulin class corresponded well with the original titres. Except for one patient, the highest titres were present in the IgM fraction but there were marked reactions with IgG also. The one control serum tested had antibody to Escherichia coli in the

\section{Discussion}

Although antibodies to Escherichia coli have been demonstrated in the serum of normal subjects (Cohen and Norins, 1968; Brown and Lee, 1973), and in patients with inflammatory bowel disease (Perlmann et al., 1965; Lagercrantz et al., 1968; Thayer et al., 1969; Bull and Ignaczak, 1973; Brown and Lee, 1973), the number of serotypes previously tested have always been very few. There are 159 internationally accepted Escherichia coli serotypes and these all provide specific $\mathrm{O}$-antigens based on the heat stable lipopolysaccharide of the cell wall of the bacterium. Various serotypes of Escherichia coli are present in different subjects and therefore, unless all the $O$ antigens are tested, negative results may be reported. In order to avoid non-specific positive reactions, the agglutination tests were started at a dilution of $1: 200$.

The majority of patients with Crohn's disease and ulcerative colitis in this study had positive antibody reactions to a variety of Escherichia coli O-antigens. The numbers and types of Escherichia coli Oserotypes found were variable but there was no single serotype which was associated with the disease. Antibodies to commonly occurring $\mathrm{O}$ serotypes $\mathrm{O} 1, \mathrm{O} 2, \mathrm{O} 18$, and $\mathrm{O} 75$ were represented. These serotypes are generally considered to be commonly found in urinary tract infections and reflect the predominant O-groups in the faecal flora. Antibodies to $\mathrm{O} 8$ and $\mathrm{O} 9$ antigens were also present; these $\mathrm{O}$ groups have been shown to be commonly associated with plasmid carrying resistance to antimicrobial agents (Hartley et al., 1975; Howe and Linton, 1976) (Table 3). Escherichia coli 014 agglutinins were detected in only five patients and 0119 agglutinins were not present.

Previous emphasis on Escherichia coli $\mathrm{O} 14$ is due to the fact that this serotype is reported to possess on its surface, in an apparently more accessible site, an antigen present in nearly all Enterobacteriaceae, the enterobacterial common antigen of Kunin (Kunin et al., 1962). This has not been substantiated by our work since only five patients and one control subject had positive reactions against Escherichia coli 014. As most strains of 014 currently available appeared partially antigenically degraded they will have many more serological cross-reactions, giving the impression of carrying a 'common' antigen. A really smooth 014 strain gives no more cross-reactions than many other $E$. coli $O$ types in agglutination reactions performed as described in this paper, although other reactions may be observed if different serological methods such as haemagglutination are employed (Drach et al., 1972). Care had to be taken to select a smooth colony for the preparation of the specific 014 antigen and the specific antisera in rabbits. 
There were no reactions with Escherichia coli $\mathrm{O} 119$ antigen in any of the sera tested, a finding similar to those of Thayer et al. (1969) who found 0119 antibody in only one out of 91 patients; but others have suggested higher incidences (Neter et al., 1955; Kunin and Beard, 1963).

The antibody titres in patients with Crohn's disease and ulcerative colitis were higher than the control group, ranging from $1 / 400-1 / 6400$. The high numbers of Escherichia coli antibodies and the high titres demonstrable in our patients may simply be due to an increase in the antigenic load entering the system through diseased or ulcerated bowel wall in sufficient quantity to overload the liver 'filter' system. Although the patients in this study had normal liver function and normal serum immunoglobulin levels, it is known that liver disease per se may be associated with increased number of antibodies to intestinal bacteria (Prytz et al., 1973; Simjee et al., 1975).

Antibodies to Escherichia coli serotypes O136, O144, and 0124 were present in large numbers in our patients. It is of interest that OK types O124: $\mathrm{K} 72$, 0136:K78, and $0144: \mathrm{K}$ ? (B) have been shown to be associated with adult diarrhoea, causing a colitis-like syndrome, and possess properties of invasiveness characteristic of virulent Shigella strains (Sakazaki et al., 1967; Ogawa et al., 1968). It is possible that the antigenic stimulus and the degree of response may depend on the invasiveness of the organism. Whether invasive Escherichia coli strains play a role in the initiation of ulcerative colitis is uncertain at this stage and requires further elucidation.

In marked contrast to the general trend in inflammatory bowel disease, those patients whose disease was accompanied by an arthropathy had relatively low numbers of positive agglutinin reactions. One possibility is that in these patients, as well as in those with IBD and low agglutinins, the antibody present may be circulating in the form of immune complexes which are known to exist in such patients (Doe et al., 1973; Hodgson et al., 1977). It is of interest to note that of three severely ill patients in whom no antibodies were detected, one had ankylosing spondylitis and another developed severe pyoderma gangrenosum.

The bacterial antibodies detected against the various Escherichia coli serotypes tested in this study were found in both the IgM and IgG fraction of the immunoglobulins and the titres corresponded to the initial values. The serum component in patients with Crohn's disease or ulcerative colitis that causes normal lymphocytes to become cytotoxic is thought to be a cytophilic IgM antibody (Shorter et al., 1971) and it is feasible that similar antibodies to a number of Escherichia coli serotypes could be involved in causing similar reactions.

The possibility of a pathogenetic relationship between these bacterial antigens and chronic inflammatory bowel disease is weakened by the finding of such a large number of Escherichia coli serotypes in this study. It is more likely that they are secondary to the disease process. However, there still remains the possibility that these bacterial antigens may play a role in the perpetuation of the disease process and in the extraintestinal complications associated with inflammatory bowel disease.

We are extremely grateful to $\operatorname{Dr}$ A. M. Dawson for allowing us to study his patients. We also thank Miss Susan M. Keep for excellent technical assistance and Miss Annie Lai for secretarial help. We are grateful to the Action Research for Crippled Children for financial support.

\section{References}

Asherson, G. L., and Holborow, E. J. (1966). Autoantibody production in rabbits. VII. Autoantibodies to gut produced by the injection of bacteria. Immunology, 10, 161-167.

Bettelheim, K. A. (1969). Investigation into the pathogenicity of $E$. coli in human infections. Ph.D. Thesis: University of London.

Bettelheim, K. A., Faiers, M., and Shooter, R. A. (1972). Serotypes of Escherichia coli in normal stools. Lancet, 2, 1224-1226.

Broberger, O., and Perlmann, P. (1959). Autoantibodies in human ulcerative colitis. Journal of Experimental Medicine, 110, 657-674.

Brown, W. R., and Lee, E. M. (1973). Radioimmunologic measurements of naturally occurring bacterial antibodies. 1. Human serum antibodies reactive with Escherichia coli in gastrointestinal and immunologic disorders. Journal of Laboratory and Clinical Medicine, 82, 125-136.

Bull, D. M., and Ignaczak, T. F. (1973). Enterobacterial common antigen-induced lymphocyte reactivity in inflammatory bowel disease. Gastroenterology, 64, 43-50.

Cohen, I. R., and Norins, L. C. (1968). Antibodies of the $\mathrm{IgG}, \mathrm{IgM}$ and IgA classes in newborn and adult sera reactive with gram-negative bacteria. Journal of Clinical Investigation, 47, 1053-1062.

Desmyter, J., South, M. A., and Rawls, W. E. (1971). The IgM antibody response in rubella during pregnancy. Journal of Medical Microbiology, 4, 107-114.

Doe, W. F., Brown, D. L., and Booth, C. C. (1973). Evidence for complement-binding immune complexes in adult coeliac disease, Crohn's disease and ulcerative colitis. Lancet, 1, 402-403.

Drach, G. W., Reed, W. P., and Williams, R. C,. Jr. (1972). Antigens common to human and bacterial cells. II. E. coli O14, the common Enterobacteriaceae antigen, blood groups A and B, and E. coli O86. Journal of Laboratory and Clinical Medicine, 79, 38-46.

Ewing, W. H. (1956-57). Production of Escherichia coli antiserum. Public Health Laboratory, 138, 14-15.

Goldgraber, M. B., and Kirsner, J. B. (1958). The histopathology of the experimental hypersensitive state in the gastrointestinal tract. Archives of Internal Medicine, 102 134-148.

Hartley, C. L., Howe, K., Linton, A. H., and Richmond, 
M. H. (1975). Distribution of $\mathbf{R}$ plasmids among the $\mathbf{O}$ antigens types of Escherichia coli isolated from human and animal sources. Antimicrobial Agents and Chemotherapy, 8, 122-131.

Hodgson, J. J. F., Potter, J., and Jewell, D. P. (1977). Immune complexes in ulcerative colitis and Crohn's disease. Clinical and Experimental Immunology, 29, 187.

Howe, K., and Linton, A. H. (1976). The distribution of Oantigen types of Escherichia coli in normal calves, compared with man, and their R plasmid carriage. Journal of Applied Bacteriology, 40, 317-330.

Kunin, C. M., and Beard, M. V. (1963). Serological studies of O-antigens of Escherichia coli by means of the haemagglutination test. Journal of Bacteriology, 85, 541-548.

Kunin, C. M., Beard, M. V., and Halmagyi, N. E. (1962). Evidence for a common hapten associated with endotoxin fractions of Escherichia coli and other Enterobacteriaceae. Proceedings of the Society for Experimental Biology and Medicine, 111, 160-166.

Lagercrantz, R., Hammarström, S., Perlmann, P., and Gustafsson, B. E. (1968). Immunological studies in ulcerative colitis. Journal of Experimental Medicine, 128, 1339-1352.

Neter, E., Westphal, O., Lüderitz, O., Gino, R. M., and Gorzynski, E. A. (1955). Demonstration of antibodies against enteropathogenic Escherichia coli in sera of children of various ages. Pediatrics, 16, 801-808.

Ogawa, H., Nakamura, A., and Sakazaki, R. (1968). Pathogenic properties of 'enteropathogenic' Escherichia coli from diarrhoeal children and adults. Japanese Journal of Medical Science and Biology, 21, 333-349.

Perlmann, P., Hammarström, S., Lagercrantz, R., and Campbell, D. (1967). Autoantibodies to colon in rats and human ulcerative colitis: cross reactivity with Escherichia coli 0:14 antigen. Proceedings of the Society for Experimental Biology and Medicine, 125, 975-980.

Perlmann, P., Hammarström, S., Lagercrantz, R., and
Gustafsson, B. E. (1965). Antigen from colon of germfree rats and antibodies in human ulcerative colitis. Annals of the New York Academy of Sciences, 124, 377-394.

Prytz, H., Björneboe, M., Örskov, F., and Hilden, M. (1973). Antibodies to Escherichia coli in alcoholic and non-alcoholic patients with cirrhosis of the liver or fatty liver. Scandinavian Journal of Gastroenterology, 8, 433-438.

Sakazaki, R., Tamura, K., and Saito, M. (1967). Enteropathogenic Escherichia coli associated with diarrhoea in children and adults. Japanese Journal of Medical Science and Biology, 20, 387-399.

Shooter, R. A., Bettelheim, K. A., Lennox-King, S. M. J., and O'Farrell, S. (1977). Escherichia coli serotypes in the faeces of healthy adults over a period of several months. Journal of Hygiene, 78, 95-98.

Shorter, R. G., Huizenga, K. A., ReMine, S. G., and Spencer, R. J. (1970). Effects of preliminary incubation of lymphocytes with serum on their cytotoxicity for colonic epithelial cells. Gastroenterology, 58, 843-850.

Shorter, R. G., Huizenga, K. A., Spencer, R. J., Aas, J., and Guy, S. K. (1971). Inflammatory bowel disease: cytophilic antibody and the cytotoxicity of lymphocytes for colonic cells in vitro. American Journal of Digestive Diseases, 16, 673-680.

Simjee, A. E., Hamilton-Miller, J. M. T., Thomas, H. C., Brumfitt, W., and Sherlock, S. (1975). Antibodies to Escherichia coli in chronic liver diseases. Gut, 16, 871-875.

Tabaqchali, S., Howard, A., Teoh-Chan, C. H., Bettelheim, K. A., and Gorbach, S. L. (1977). Distribution of Escherichia coli serotypes throughout the gastrointestinal tract in patients with intestinal disorder. Gut, 18, 351-355.

Thayer, W. R., Jr., Brown, M., Sangree, M. H., Katz, J., and Hersh, T. (1969). Escherichia coli O:14 and colon hemagglutinating antibodies in inflammatory bowel disease. Gastroenterology, 57, 311-318.

Wright, R., and Truelove, S. C. (1966). Auto-immune reactions in ulcerative colitis. Gut, 7, 32-40. 